\title{
Piper betle L. Modulates Senescence-Associated Genes Expression in Replicative Senescent Human Diploid Fibroblasts
}

\author{
Lina Wati Durani, ${ }^{1}$ Shy Cian Khor, ${ }^{1}$ Jen Kit Tan, ${ }^{1}$ Kien Hui Chua, \\ Yasmin Anum Mohd Yusof, ${ }^{1}$ and Suzana Makpol ${ }^{1}$ \\ ${ }^{1}$ Department of Biochemistry, Universiti Kebangsaan Malaysia Medical Centre, Level 17, Preclinical Building, Jalan Yaacob Latif, \\ Bandar Tun Razak, 56000 Cheras, Kuala Lumpur, Malaysia \\ ${ }^{2}$ Department of Physiology, Universiti Kebangsaan Malaysia Medical Centre, Level 18, Preclinical Building, Jalan Yaacob Latif, \\ Bandar Tun Razak, 56000 Cheras, Kuala Lumpur, Malaysia
}

Correspondence should be addressed to Suzana Makpol; suzanamakpol@ppukm.ukm.edu.my

Received 22 November 2016; Revised 31 March 2017; Accepted 13 April 2017; Published 17 May 2017

Academic Editor: Adair Santos

Copyright (C) 2017 Lina Wati Durani et al. This is an open access article distributed under the Creative Commons Attribution License, which permits unrestricted use, distribution, and reproduction in any medium, provided the original work is properly cited.

\begin{abstract}
Piper betle (PB) is a traditional medicine that is widely used to treat different diseases around Asian region. The leaf extracts contain various bioactive compounds, which were reported to have antidiabetic, antibacterial, anti-inflammatory, antioxidant, and anticancer effects. In this study, the effect of $\mathrm{PB}$ aqueous extracts on replicative senescent human diploid fibroblasts (HDFs) was investigated by determining the expressions of senescence-associated genes using quantitative PCR. Our results showed that PB extracts at $0.4 \mathrm{mg} / \mathrm{ml}$ can improve cell proliferation of young (143\%), presenescent (127.3\%), and senescent (157.3\%) HDFs. Increased expressions of PRDX6, TP53, CDKN2A, PAK2, and MAPK14 were observed in senescent HDFs compared to young and/or presenescent HDFs. Treatment with PB extracts modulates the transcriptional profile changes in senescent HDFs. By contrast, expressions of SOD1 increased, whereas GPX1, PRDX6, TP53, CDKN2A, PAK2, and MAPK14 were decreased in PB-treated senescent HDFs compared to untreated senescent HDFs. In conclusion, this study indicates the modulation of PB extracts on senescenceassociated genes expression of replicative senescent HDFs. Further studies warrant determining the mechanism of PB in modulating replicative senescence of HDFs through these signaling pathways.
\end{abstract}

\section{Introduction}

In 1961, Hayflick and Moorhead discovered the finite cell growth of fibroblasts after multiple division, later called replicative senescence, which serves as model to study aging [1]. Replicative senescence is an irreversible growth arrest due to limited cell expansion number which was observed in human diploid fibroblasts (HDFs) and other cell types including astrocytes [2] and smooth muscle cells [3]. Regardless of the cell types, replicative senescence affects normal biological system and is represented by various classical features. For instance, cell becomes enlarged and flattened $[2,4]$, with increased activity of senescence-associated betagalactosidase (SA- $\beta$-Gal) [5], increased damaged DNA, and shortening of telomere length and ultimately cells are growtharrested [6].
Free radical theory of aging postulated the involvement of oxidative stress in aging development [7]. Increased oxidative stress is attributed by the endogenous and exogenous free radicals formation due to normal metabolism and exposure to environmental oxidants [8]. Therefore, a balance between production of free radicals and cellular antioxidants defence is required in preventing oxidative stress. Antioxidants can either naturally present in our body, in the form of enzymes such as superoxide dismutases (SODs), catalase (CAT), and glutathione peroxidase (GPX), or consumed from the diet such as vitamin E, vitamin C, and carotenoids [9]. Elevated free radicals generation and ineffective antioxidant defence have been observed with increasing age. Excessive free radical impairs the cellular redox status by either causing irreversible damage to DNA, protein, and lipid or interfering with the regulation of redox signaling at transcriptional or 
translational levels [10]. Thus, antioxidant supplementation becomes popular, with the intention to improve the redox balance, achieve the desired longevity, and increase health span. However, does this antioxidant supplementation work as expected as antiaging agents and what is the mechanism involved?

More recently, herbal plants have gained worldwide popularity as antioxidant supplements to combat oxidative damage and act as antiaging agent $[11,12]$. Betel vine (Piper betle Linn.; PB) is a member of Piperaceae family available in South and Southeast Asia including Malaysia throughout the year. This perennial creeper plant has glossy heart shaped and yellowish green leaves with a strong pungent aromatic flavor [13]. It has been known as a traditional medicine that has curative properties for pain and swelling, throat and lung problems, and oral hygiene $[14,15]$. PB extracts contain various bioactive phenolic compounds, such as hydroxychavicol [16], chavibetol [17], and allylpyrocatechol [18], which are regarded as having valuable biological effects. In the past decade, resurgence of interest in medicinal plants contributed more researches on the effects of PB extracts and their bioactive compounds, including wound healing [19] and antioxidant [13] antidiabetic [20], antibacterial and antifungal $[21,22]$, and anti-inflammatory [23] effects. Some effects of PB leaves are even being patent filed for their anticancer and immunomodulatory properties [24, 25]. Although many studies have reported the valuable effects of $\mathrm{PB}$, research is still ongoing to discover the mechanisms involved, especially its role in preventing cellular aging. Hence, the present study aimed to evaluate the molecular mechanism of PB extracts in delaying replicative senescence of HDFs by focusing on its senescence-associated genes expression modulation and further insight into the link between these genes and cellular aging.

\section{Materials and Methods}

2.1. Cell Culture and the Induction of Replicative Senescence. This research was approved by the Research Ethics Committee of Universiti Kebangsaan Malaysia (UKMREC) (Approval Project Code: FF-289-2011). Primary HDFs were derived from foreskins of three different male subjects aged between 9 and 12 years after circumcision. Written informed consents were obtained from subjects' parents. The samples were processed and cultured as described in Makpol et al. [6]. Serial passaging was carried out with expansion degree of $1: 4$ when the culture achieved 80 to $90 \%$ confluency until HDFs reached senescence. As in previous report [6], HDFs at passage 4 (young cell, population doublings, PD $<12$ ), passage 15 (presenescent cell, $30<\mathrm{PD}<40$ ), and passage 30 (senescent cell, PD $>55$ ) were used for the subsequent experiments. Each stage of cells was divided into two groups, which were nontreated group and PB extracts-treated group.

2.2. PB Extracts Preparation. PB leaves were obtained from Kampung Lebu, Bentong, Pahang, Malaysia. The extraction method was according to Pin and colleagues [26] with some amendments. Briefly, the leaves were dried under the sun and then made up to a $10 \%$ solution by mixing $200 \mathrm{~g}$ of grinded leaves with 2 liters of ultrapure water. The suspension was heated to $60^{\circ} \mathrm{C}$ for 2 hours by using Soxhlet extractor (Thermo Scientific, UK). After that, the extracts were filtered by filter paper and kept at $-20^{\circ} \mathrm{C}$ for 3 days. Then, by using a freeze dryer system (Labconco, USA), the PB extracts were dried into powder form and stored at $4^{\circ} \mathrm{C}$. For the subsequent experiment, stock of $\mathrm{PB}$ extracts was prepared in complete culture medium at a concentration of $1 \mathrm{mg} / \mathrm{ml}$ followed by serial dilution to get the desired $\mathrm{PB}$ extracts concentration.

2.3. Cell Proliferation Assay. Cell proliferation assay was performed by using CellTiter $96^{\circledR} \mathrm{AQ}_{\text {ueous }}$ Nonradioactive Cell Proliferation Assay (Promega, USA), according to the protocol given by manufacturer. This colorimetric assay was made up by 3-(4,5-dimethylthiazol-2-yl)-5-(3-carboxymethoxyphenyl)-2-(4-sulfophenyl)-2H-tetrazolium (MTS) and phenazine methosulfate (PMS). Briefly, $2 \times 10^{4}$ of cells were plated in 96-well plate (Becton Dickinson, USA) and incubated overnight. A serial dilution of $\mathrm{PB}$ extracts at concentrations starting from $0.2 \mathrm{mg} / \mathrm{ml}$ until $0.8 \mathrm{mg} / \mathrm{ml}$ was prepared in culture medium and used to treat the cells. After 24-hour incubation, $20 \mu \mathrm{l}$ of MTS solution was added and cells were further incubated for 2 hours. The absorbance of the formazan produced was measured at $490 \mathrm{~nm}$ by using a tunable microplate reader (VersaMax Molecular Devices, USA).

2.4. Primer Design. Primers for human GAPDH, SOD1, SOD2, CAT, GPX1, CCS, PRDX6, FOXO3, CDKN2A, PAK2, TP53, MAPK14, and JUN were designed by using GenBank database sequences and Primer 3 software [27] (http://bioinfo.ut.ee/primer3-0.4.0/). With Basic Local Alignment Search Tool (BLAST), the primers were aligned. The efficiency and specificity of these primers were confirmed by evaluating the melt curve produced in qRT-PCR. All of the primer sequences were shown in Table 1.

2.5. Total RNA Extraction. TRI Reagent ${ }^{\circledR}$ (Molecular Research Center, USA) was used to extract the RNA according to manufacturer's instructions. Firstly, $1 \mathrm{ml}$ of TRI reagent was added and collected into a tube after 5 minutes. To separate the cell lysate, chloroform was added and homogenized. The clear layer of the solution was collected after being centrifuged at $4^{\circ} \mathrm{C}$. To precipitate the RNA, Polyacryl Carrier (Molecular Research Center, USA) was added following the isopropanol. The extracted RNA (white pellet) was washed with 75\% ethanol and air-dried for 15 minutes. Sufficient amount of DNase RNase free distilled water (Gibco, USA) was added to dissolve the RNA and then stored at $-80^{\circ} \mathrm{C}$. By using NanoDrop ND-1000 (Thermo Scientific, USA), the yield and purity of the extracted RNA were examined.

2.6. Quantitative Real-Time Polymerase Chain Reaction ( $q R T$ $P C R$ ). The expression levels of SOD1, SOD2, CAT, GPX1, CCS, PRDX6, FOXO3, CDKN2A, PAK2, TP53, MAPK14, and 
TABLE 1: Primer sequences for quantitative real-time PCR.

\begin{tabular}{lccc}
\hline Target genes & Forward primer $\left(5^{\prime}-3^{\prime}\right)$ & Reverse primer $\left(5^{\prime}-3^{\prime}\right)$ & Product size $(\mathrm{bp})$ \\
\hline GAPDH & tcc ctg agc tga acg gga ag & gga gga gtg ggt gtc gct gt & 217 \\
SOD1 & gaa ggt gtg ggg aag cat ta & aca ttg ccc aag tct cca ac & 174 \\
SOD2 & cgt cac cga gga gaa gta cc & ctg att tgg aca agc agc aa & 312 \\
CAT & cgt gct gaa tga gga aca ga & agt cag ggt gga cct cag tg & 119 \\
GPX1 & cca agc tca tca cct ggt ct & tcg atg tca atg gtc tgg aa & 127 \\
PRDX6 & cgt gtg gtg ttt gtt ttt gg & tgc tgt cag ctg gag aga ga & 120 \\
CCS & act tta acc ctg atg gag cat ct & agg tca tct tct ccc tca tca at & 181 \\
FOXO3 & gca agc aca gag ttg gat ga & cag gtc gtc cat gag gtt tt & 185 \\
TP53 & gga aga gaa tct ccg caa gaa & agc tct cgg aac atc tcg aag & 177 \\
PAK2 & gat ggc acc aga ggt ggt ta & tcc cga aat att ggg gaa ag & 198 \\
CDKN2A & agt gag ggt ttt cgt ggt tca c & cca tca tca tga cct ggt ctt cta & 150 \\
MAPK14 & ggg gca gat ctg aac aac at & gag cca gtc caa aat cca ga & 190 \\
JUN & gtc tac gca aac ctc agc aac & act gtc tga ggc tcc tcc ttc & 191 \\
\hline
\end{tabular}

$J U N$ were quantitatively analyzed by using one-step qRTPCR technique. Each target gene expression was normalized by reference gene, GAPDH [28]. The reaction was performed using $100 \mathrm{ng}$ of total RNA at a concentration of $400 \mathrm{nM}$ for each primer and iScript One-Step RT-PCR kit with SYBR Green (Bio-Rad, Canada) according to the manufacturer's instructions. The master mix was prepared; then reactions were carried out by using iQ5 Bio-Rad iCycler with programmed reaction profile as follows: cDNA synthesis for $30 \mathrm{~min}$ at $50^{\circ} \mathrm{C}$; predenaturation for $2 \mathrm{~min}$ at $94^{\circ} \mathrm{C}$; and PCR amplification for $38 \mathrm{cycles}$ of $30 \mathrm{sec}$ at $94^{\circ} \mathrm{C}$ and $30 \mathrm{sec}$ at $60^{\circ} \mathrm{C}$. After the end of the last cycle, the melt curve was generated at $95^{\circ} \mathrm{C}$ for $1 \mathrm{~min}, 55^{\circ} \mathrm{C}$ for $1 \mathrm{~min}$, and $60^{\circ} \mathrm{C}$ for $10 \mathrm{sec}(70 \mathrm{cycles}$, increase in set point temperature after cycle 2 by $0.5^{\circ} \mathrm{C}$ ). The relative expression values of target genes were calculated using the $2^{-\Delta \Delta \mathrm{Ct}}$ method.

2.7. Statistical Analysis. Each experiment was performed in triplicate using HDFs from three different biological subjects. Data was analyzed by one-way analysis of variance (ANOVA) followed by post hoc multiple comparison tests. A $p$ value less than $0.05(p<0.05)$ was considered as statistically significant.

\section{Results}

3.1. Dose Response Curve of PB Extracts on HDFs' Cell Proliferation. The results showed that $\mathrm{PB}$ extracts significantly increased the cell proliferation of young HDFs compared to control $(p<0.05)$ at concentration ranging from $0.2 \mathrm{mg} / \mathrm{ml}$ to $0.8 \mathrm{mg} / \mathrm{ml}$ (Figure 1). Meanwhile, the cell proliferation was increased in presenescent cells when treated with $\mathrm{PB}$ extracts at $0.3 \mathrm{mg} / \mathrm{ml}$ until $0.6 \mathrm{mg} / \mathrm{ml}$ but cell proliferation decreased at $0.7 \mathrm{mg} / \mathrm{ml}$ to $0.8 \mathrm{mg} / \mathrm{ml}$. Senescent HDFs increased their cell proliferation when treated with $\mathrm{PB}$ extracts at $0.4 \mathrm{mg} / \mathrm{ml}$ until $0.8 \mathrm{mg} / \mathrm{ml}$. Therefore, we used $0.4 \mathrm{mg} / \mathrm{ml}$ of $\mathrm{PB}$ extracts for the following experiments, because, at this dosage, PB increased the cell proliferation of young $(143 \%)$, presenescent (127.3\%), and senescent (157.3\%) HDFs compared to untreated cells.

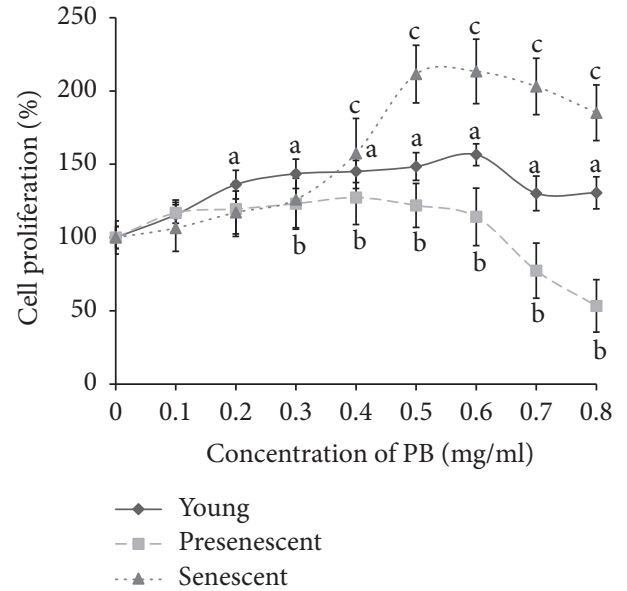

FIGURE 1: Dose response of PB extracts on proliferation of young, presenescent, and senescent HDFs. a denotes $p<0.05$ compared to control young HDFs, $\mathrm{b}$ denotes $p<0.05$ compared to control presenescent HDFs, and $c$ denotes $p<0.05$ compared to control senescent HDFs. Data are presented as mean \pm SD $(n=3)$.

3.2. Effects of Replicative Senescence on Senescence-Associated Genes Expression. We determined several antioxidant-associated genes expression (SOD1, SOD2, CAT, GPX1, CCS, and PRDX6) in different PD stages of HDFs (Figure 2). The expression of SOD1 in presenescent HDFs was lower as compared to young control (Figure 2(a)). However, SOD2, $C A T$, and GPX1 expressions were not significantly different between young, presenescent, and senescent groups (Figures 2(b), 2(c), and 2(d)). CCS was downregulated in presenescent HDFs compared to young control and significantly increased in senescent HDFs as compared to presenescent HDFs (Figure 2(e)). PRDX6 expression was increased in senescent cells compared to both young and presenescent HDFs (Figure 2(f)).

Apart from the antioxidant-associated genes expression, we also investigated several stress response genes, including FOXO3, TP53, CDKN2A, PAK2, MAPK14, and JUN 


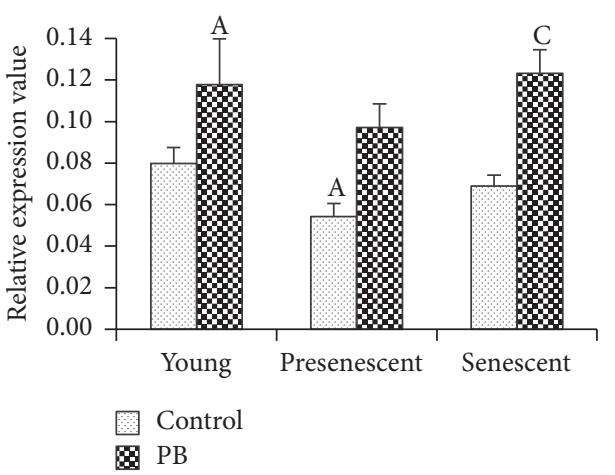

(a)

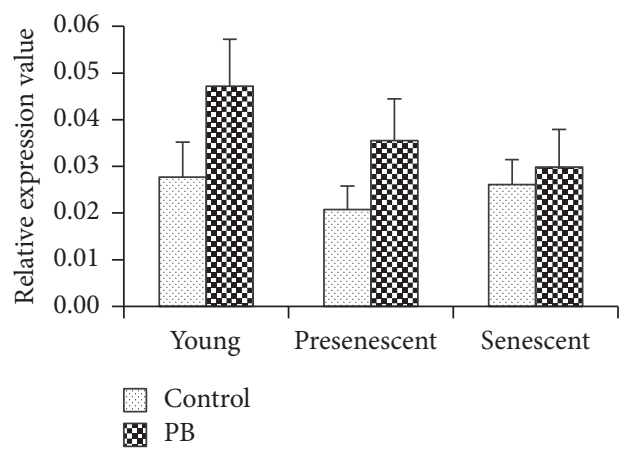

(c)

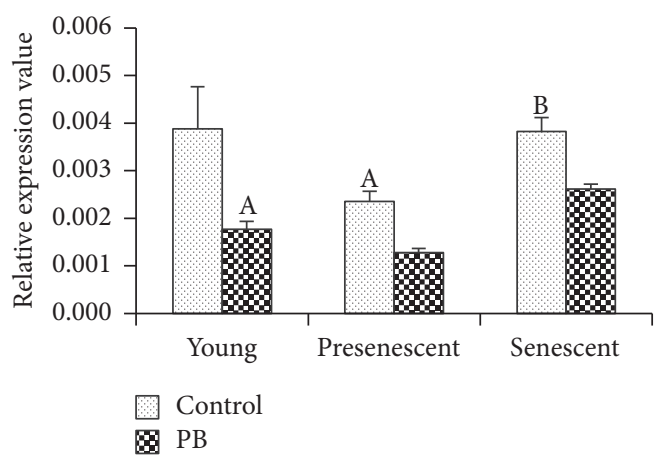

(e)

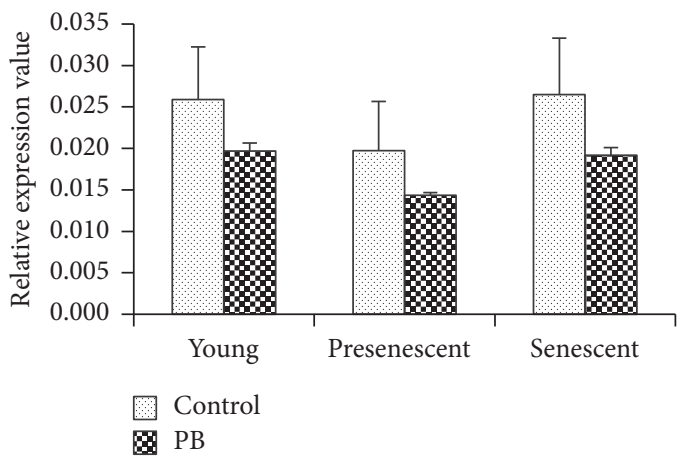

(b)

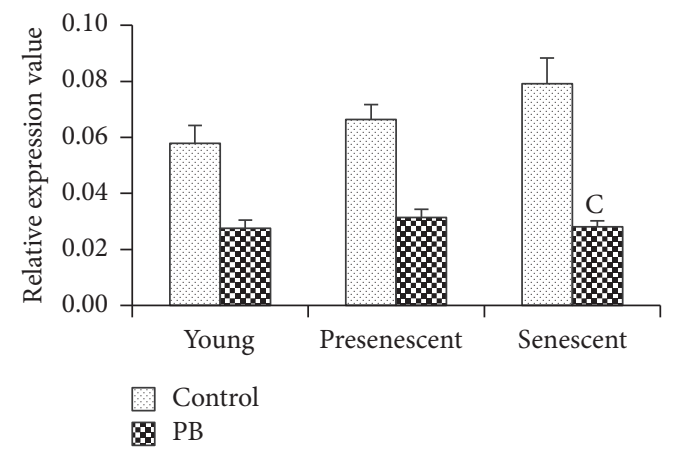

(d)

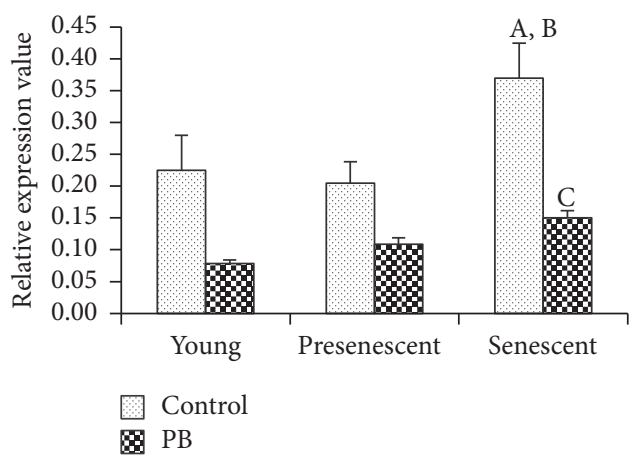

(f)

FIGURE 2: Effects of $0.4 \mathrm{mg} / \mathrm{ml} \mathrm{PB}$ extracts on antioxidant-associated genes expression of HDFs treated for 24 hours. (a) SOD1, (b) SOD2, (c) $C A T$, (d) GPX1, (e) CCS, and (f) PRDX6. A denotes $p<0.05$ compared to control for young HDFs, B denotes $p<0.05$ compared to control for presenescent HDFs, and C denotes $p<0.05$ compared to control for senescent HDFs. Data are presented as mean \pm SEM $(n=3)$.

(Figure 3). The expressions of FOXO3 and JUN were not significantly different among the 3 groups (Figures $3(\mathrm{a})$ and $3(\mathrm{f})$ ). However, TP53 expression was significantly increased in senescent HDFs compared to young and presenescent HDFs (Figure 3(b)). Expressions of CDKN2A, PAKK2, and MAPK14 were higher in senescent HDFs as compared to presenescent cells (Figures 3(c), 3(d), and 3(e)).

3.3. Effects of PB Extracts on Senescence-Associated Genes Expression. Our data showed that $\mathrm{PB}$ extracts increased SOD1 expression in both young and senescent cells compared to untreated controls, respectively (Figure 2(a)). PB extracts downregulated both GPX1 and PRDX6 in senescent cells compared to untreated senescent cells (Figures 2(d) and 2(f)).
PB extracts treatment decreased the expression of CCS in young HDFs compared to untreated young cells (Figure 2(e)). Expressions of SOD2 and CAT were not different between $\mathrm{PB}$ extracts-treated and untreated groups (Figures 2(b) and 2(c)).

For the stress response genes, our results showed no significant change on $\mathrm{FOXO} 3$ and JUN expressions with $\mathrm{PB}$ extracts treatment compared to untreated cells (Figures 3(a) and 3(f)). However, $\mathrm{PB}$ extracts decreased the expressions of TP53 and CDKN2A in senescent HDFs compared to untreated senescent cells (Figures 3(b) and 3(c)). Treatment with $\mathrm{PB}$ extracts reduced PAK2 and MAPK14 expressions in both young and senescent cells compared to untreated controls, respectively (Figures 3(d) and 3(e)). 


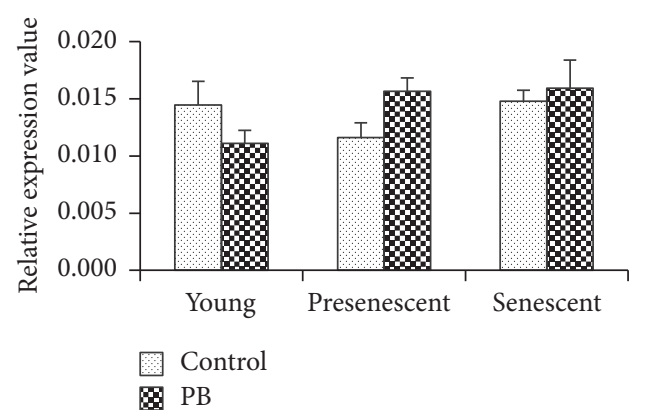

(a)

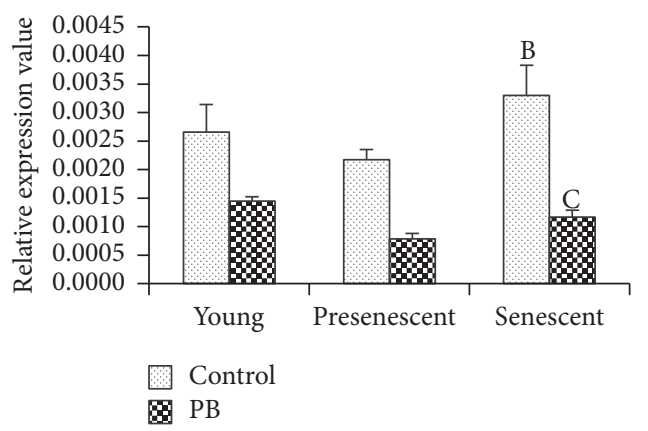

(c)

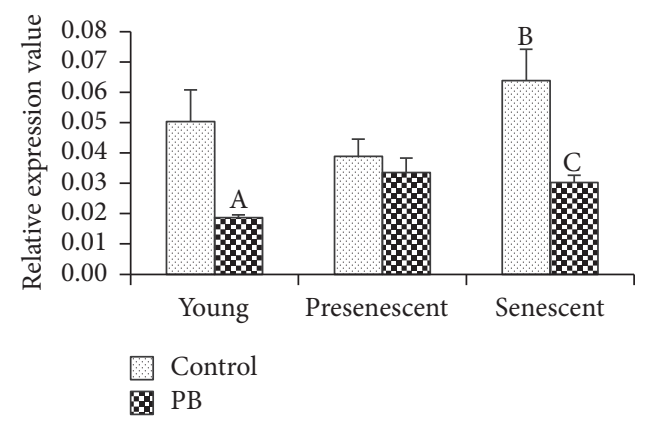

(e)

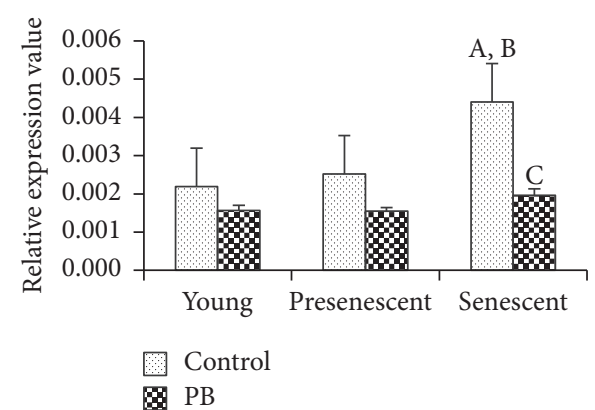

(b)

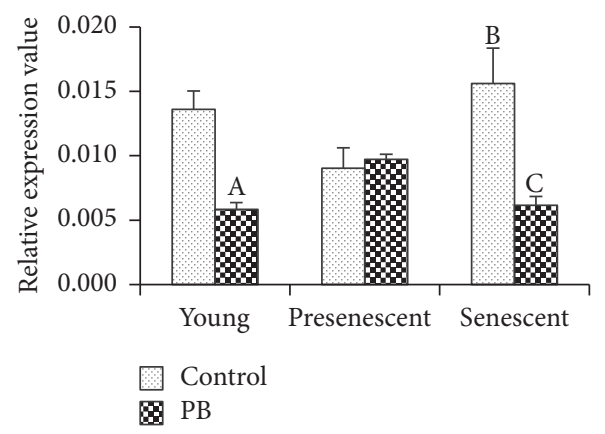

(d)

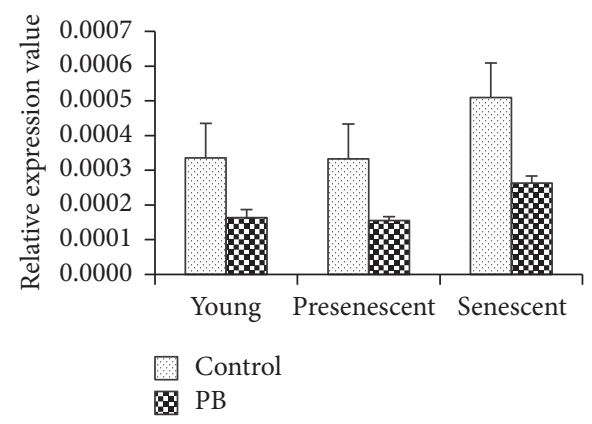

(f)

FIGURE 3: Effects of $0.4 \mathrm{mg} / \mathrm{ml} \mathrm{PB}$ extracts on stress response genes expression of HDFs treated for 24 hours. (a) FOXO3, (b) TP53, (c) CDKN2A, (d) PAK2, (e) MAPK14, and (f) JUN. A denotes $p<0.05$ compared to control for young HDFs, B denotes $p<0.05$ compared to control for presenescent HDFs, and C denotes $p<0.05$ compared to control for senescent HDFs. Data are presented as mean \pm SEM $(n=3)$.

\section{Discussion}

Aging is normally associated with oxidative stress, which then induces cellular response cascades that can be represented by transcriptional profile. Our study had focused on the effects of $\mathrm{PB}$ extracts on replicative senescence-associated genes expression of human diploid fibroblasts. PB extracts exert potent antioxidant properties that are able to scavenge free radicals $[13,29]$. Allylpyrocatechol, the most potent phenolic compound in $\mathrm{PB}$ extracts, might play a role in eliminating the free radicals insults along with increased cellular antioxidants [30]. The senescence biomarker, senescenceassociated $\beta$-galactosidase, was significantly reduced with $\mathrm{PB}$ extracts treatment in senescent HDFs, indicating the potential of $\mathrm{PB}$ extracts in regulating the process of replicative senescence [31]. The free radical scavenging activity of PB may be responsible for the revival of HDFs, especially in the oxidative damaged senescent cells. However, the molecular defense mechanism of $\mathrm{PB}$ extracts in senescent cells is poorly understood.

Generally, organism produces free radicals when undergoing normal oxidative metabolism. Excessive production of free radicals is expected to result in adverse changes that accumulate with age, concomitantly induceing stress signaling response in the cell. In order to compensate the oxidative damage, organism possesses an antioxidant defense mechanism that mainly is comprised of antioxidant enzymes. For instance, SODs (Cu/ZnSOD and MnSOD) in our body play a key role in eliminating superoxide radicals $\left(\mathrm{O}_{2}{ }^{-}\right)$, while CAT and GPX1 catalyze the decomposition of hydrogen peroxide $\left(\mathrm{H}_{2} \mathrm{O}_{2}\right)$ to water $\left(\mathrm{H}_{2} \mathrm{O}\right)$ and oxygen $\left(\mathrm{O}_{2}\right)$ [9]. However, this study showed no significant change in the expressions of SOD1 (Cu/ZnSOD), SOD2 (MnSOD), CAT, and GPX1 in between young and senescent cells. These findings 
are comparable to the findings obtained by Hazane and others [32], who observed no significant difference in antioxidantassociated genes expression in primary HDFs from three PD groups. Copper chaperone for superoxide dismutase 1 (CCS1) is required for the maintenance of redox balance by facilitating copper insertion into SOD1 $[33,34]$. In this study, the role of CCS1 remained difficult to interpret as its expression was increased in young and senescent cells as compared to presenescent cells. PRDX6 is an alternative peroxidase that uses GSH as an electron donor to reduce $\mathrm{H}_{2} \mathrm{O}_{2}$ [35]. Our result showed that PRDX6 expression was increased in senescent HDFs, suggesting that increased PRDX6 expression may be needed to protect the senescent cells from oxidative stress.

The family of forkhead class $\mathrm{O}$ (FOXO) proteins regulate diverse physiological processes, including oxidative stress, cell cycle arrest, and apoptosis, which are mediated through a distinct forkhead DNA-binding domain [36, 37]. Downregulation of $F O X O 3 A$ gene and protein expression by siRNA [38] and inhibition of FOXO3A by overexpression of Akt [39] have been shown to accelerate senescence in HDFs. In addition, knockout of FOXO3A promoted replicative senescence in mouse embryonic fibroblast [40] and inactive form of FOXO3A was increased in replicative senescent rat cardiac microvascular endothelial cells [41]. In this study, however, FOXO3A gene expression remained unchanged among $3 \mathrm{PD}$ groups, suggesting that the role of $\mathrm{FOXO} 3 \mathrm{~A}$ during replicative senescence might depend on types of cellular models studied.

Cell growth arrest in senescent cells could be triggered by DNA damage via $\mathrm{p} 53$ and/or p16 pathways. In p53 pathway, DNA double-strand breaks activated p38 MAPK (encoded by MAPK14) which acts as a sensor for DNA damage [42]. p38 MAPK phosphorylates p53 which causes the dissociation of $\mathrm{p} 53$ form $\mathrm{Mdm} 2$ and thus promotes p53 stabilization and accumulation. Active p53 induces the expressions of $C D K N 1 A$ and $P A K$ which suppress cell cycle progression. In addition, expressions of p53 and p21 are negatively regulated by c-JUN [43]. When CDKN2A (encoded for p16 protein) expression is induced, p16 prevents retinoblastoma (pRB) phosphorylation and activates it to bind with E2F transcription factor and thus promotes cell cycle arrest [44]. Previously, we have shown that DNA damage was accumulated and cell growth was arrested at G1 phase during replicative senescence of HDFs [6]. Our results in this study showed that expressions of MAPK14, TP53, PAK2, and CDKN2A were increased in senescent cells, suggesting that p53 and p16 pathways may be involved in the cell growth arrest of replicative senescent HDFs.

This study showed that treatment with $\mathrm{PB}$ extracts increased SOD1 expression in senescent cells, which is similar to the findings on an animal study which reported that the activity of liver SOD increased after 2 weeks of oral supplementation of $\mathrm{PB}$ extracts [45]. In Nrf2 (transcription factor for SOD1) knockout mouse embryonic fibroblast, $\mathrm{PB}$ extracts were able to induce SOD1 gene expression [46]. Our data suggested that $\mathrm{PB}$ extracts may be involved in cellular antioxidant defense system of replicative senescent cells by regulating gene expression of antioxidant enzyme.
Conversely, $\mathrm{PB}$ extracts treatment reduced the expressions of GPX1 and PRDX6 in senescent HDFs. In agreement with Dasgupta and De [13], PB extracts have free radical scavenging property, which reduces lipid peroxidation. Thus, the presence of this potent free radical scavenger in PBtreated cells may lead to the decreased need on endogenous antioxidant enzymes.

$\mathrm{PB}$ was able to prevent radiation-induced DNA damage and promote cell proliferation [17]. Allylpyrocatechol and chavibetol in PB extracts were reported to be able to protect liver mitochondria from photosensitization-induced lipid peroxidation; meanwhile, allylpyrocatechol alone was found to inhibit type II photosensitization damage in fibroblasts [18]. This proposed that the active compounds in PB extracts could eliminate the stress stimulants in cells. Our data showed that TP53, CDKN2A, PAK2, and MAPK14 expressions were decreased in senescent cells treated with $\mathrm{PB}$ extracts, indicating that DNA damage via 53 and p16 pathways is suppressed. These data suggest that DNA damage and cell cycle arrest may be ameliorated in senescent cells due to the reduced oxidative stress.

Taken together, as illustrated in Figure 4, we proposed that $\mathrm{PB}$ extracts increased the proliferation of senescent cells by alleviating the oxidative stress during replicative senescence via increasing of SOD1 expression to scavenge free radicals. Treatment with $\mathrm{PB}$ extracts reduced the expressions of GPX1 and PRDX6, suggesting that the needs on endogenous antioxidant enzymes may be reduced. After enhancing the antioxidant status, the extent of DNA damage and cell cycle arrest will be decreased and thus results in the downregulation of TP53, CDKN2A, PAK2, and MAPK14 expressions.

\section{Conclusion}

$\mathrm{PB}$ extracts modulate the expressions of gene involved in antioxidant defense (SOD1, GPX1, and PRDX6), DNA damage, and cell cycle arrest (TP53, CDKN2A, PAK2, and $M A P K 14)$ signaling pathways during replicative senescence of HDFs. Further studies are needed to characterize the active compounds in $\mathrm{PB}$ extracts which are responsible for the gene regulation during the replicative senescence of HDFs and to determine the functional roles of these genes in mediating the effect of $\mathrm{PB}$ during replicative senescence of HDFs.

\section{Abbreviations}

AP-1: Activator protein 1

CDK: Cyclin-dependent kinase

FOXO3: Forkhead box $\mathrm{O} 3$

GADPH: Glyceraldehyde 3-phosphate dehydrogenase

GSH: Reduced glutathione

GSSG: Oxidized glutathione

HDFs: Human diploid fibroblasts

MAPK: Mitogen-activated protein kinase

PAK: p21-activated kinase

PD: $\quad$ Population doubling

PRDX6: Peroxiredoxin 6 

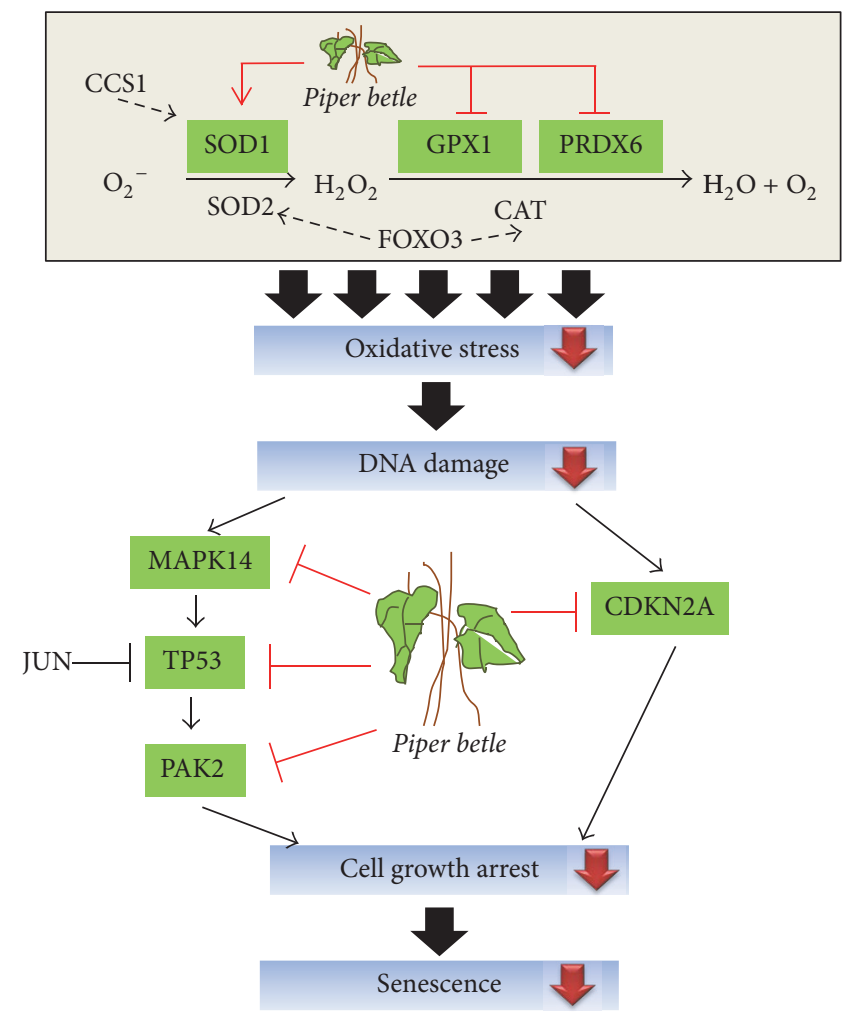

FIgURE 4: An illustration on the mechanism of PB extracts in ameliorating replicative senescence of HDFs. PB extracts upregulate SOD1 expression which results in reduced oxidative stress. Reduced oxidative stress spares the expressions of GPX1 and PRDX6, decreases DNA damage, suppresses gene expressions of TP53 and CDKN2A (p16) signaling pathways, promotes cell cycle progression, and thus increases cell proliferation of senescent HDFs.

qRT-PCR: Quantitative real-time polymerase chain reaction

SIPS: $\quad$ Stress-induced premature senescence.

\section{Conflicts of Interest}

The authors declare that they have no conflicts of interest.

\section{Authors' Contributions}

Suzana Makpol designed the experiment, analyzed and interpreted the data, and revised the manuscript. Lina Wati Durani performed the experiment and analyzed and interpreted the data. Shy Cian Khor and Jen Kit Tan analyzed, interpreted, and drafted the manuscript. Kien Hui Chua participated in HDFs primary culture optimization. Yasmin Anum Mohd Yusof provided the Piper betle and helped in the extraction and treatment of cells. All authors read and approved the final manuscript.

\section{Acknowledgments}

This study was funded by Universiti Kebangsaan Malaysia under research university Grant nos. GUP-SK-07-21-043 and FF-289-2011.

\section{References}

[1] L. Hayflick and P. S. Moorhead, "The serial cultivation of human diploid cell strains," Experimental Cell Research, vol. 25, no. 3, pp. 585-621, 1961.

[2] A. Bitto, C. Sell, E. Crowe et al., "Stress-induced senescence in human and rodent astrocytes," Experimental Cell Research, vol. 316, no. 17, pp. 2961-2968, 2010.

[3] V. Bassaneze, A. A. Miyakawa, and J. E. Krieger, "A quantitative chemiluminescent method for studying replicative and stressinduced premature senescence in cell cultures," Analytical Biochemistry, vol. 372, no. 2, pp. 198-203, 2008.

[4] K. A. Cho, J. R. Sung, S. O. Yoon et al., "Morphological adjustment of senescent cells by modulating caveolin-1 status," Journal of Biological Chemistry, vol. 279, no. 40, pp. 4227042278, 2004.

[5] G. P. Dimri, X. Lee, G. Basile et al., "A biomarker that identifies senescent human cells in culture and in aging skin in vivo," Proceedings of the National Academy of Sciences of the United States of America, vol. 92, no. 20, pp. 9363-9367, 1995.

[6] S. Makpol, L. W. Durani, K. H. Chua, Y. A. Mohd Yusof, and W. Z. Wan Ngah, "Tocotrienol-rich fraction prevents cell cycle arrest and elongates telomere length in senescent human diploid fibroblasts," Journal of Biomedicine and Biotechnology, vol. 2011, Article ID 506171, 11 pages, 2011.

[7] D. Harman, "Aging: a theory based on free radical and radiation chemistry," Journal of Gerontology, vol. 11, no. 3, pp. 298-300, 1956. 
[8] B. Poljšak, P. Jamnik, P. Raspor, M. Pesti, and J. Nriagu, "Oxidation-antioxidation-reduction processes in the cell: impacts of environmental pollution," pp. 300-306, Elsevier, Burlington, MA, USA, 2011.

[9] T. Finkel and N. J. Holbrook, "Oxidants, oxidative stress and the biology of ageing," Nature, vol. 408, no. 6809, pp. 239-247, 2000.

[10] L. Gibellini, M. Pinti, M. Nasi et al., "Interfering with ROS metabolism in cancer cells: the potential role of quercetin," Cancers, vol. 2, no. 2, pp. 1288-1311, 2010.

[11] M. H. Carlsen, B. L. Halvorsen, K. Holte et al., "The total antioxidant content of more than 3100 foods, beverages, spices, herbs and supplements used worldwide," Nutrition Journal, vol. 9, no. 1, article 3, 2010.

[12] P. K. Mukherjee, N. Maity, N. K. Nema, and B. K. Sarkar, "Bioactive compounds from natural resources against skin aging," Phytomedicine, vol. 19, no. 1, pp. 64-73, 2011.

[13] N. Dasgupta and B. De, "Antioxidant activity of Piper betle L. leaf extract in vitro," Food Chemistry, vol. 88, no. 2, pp. 219-224, 2004.

[14] R. N. Chopra and I. Chopra, Indigenous drugs of India, Academic publishers, 2006.

[15] N. Kumar, P. Misra, A. Dube, S. Bhattacharya, M. Dikshit, and S. Ranade, "Piper betle Linn. A maligned pan-asiatic plant with an array of pharmacological activities and prospects for drug discovery," Current Science, vol. 99, no. 7, pp. 922-932, 2010.

[16] S. Sharma, I. A. Khan, I. Ali et al., "Evaluation of the antimicrobial, antioxidant, and anti-inflammatory activities of hydroxychavicol for its potential use as an oral care agent," Antimicrobial Agents and Chemotherapy, vol. 53, no. 1, pp. 216222, 2009.

[17] S. Bhattacharya, M. Subramanian, S. Roychowdhury et al., "Radioprotective property of the ethanolic extract of Piper betel leaf," Journal of Radiation Research, vol. 46, no. 2, pp. 165-171, 2005.

[18] S. Mula, D. Banerjee, B. S. Patro et al., "Inhibitory property of the Piper betel phenolics against photosensitization-induced biological damages," Bioorganic and Medicinal Chemistry, vol. 16, no. 6, pp. 2932-2938, 2008.

[19] S. Bhattacharya, D. Banerjee, A. K. Bauri, S. Chattopadhyay, and S. K. Bandyopadhyay, "Healing property of the Piper betel phenol, allylpyrocatechol against indomethacin-induced stomach ulceration and mechanism of action," World Journal of Gastroenterology, vol. 13, no. 27, pp. 3705-3713, 2007.

[20] L. S. R. Arambewela, L. D. A. M. Arawwawala, and W. D. Ratnasooriya, "Antidiabetic activities of aqueous and ethanolic extracts of Piper betle leaves in rats," Journal of Ethnopharmacology, vol. 102, no. 2, pp. 239-245, 2005.

[21] N. Ramji, N. Ramji, R. Iyer, and S. Chandrasekaran, "Phenolic antibacterials from Piper betle in the prevention of halitosis," Journal of Ethnopharmacology, vol. 83, no. 1-2, pp. 149-152, 2002.

[22] I. Ali, F. G. Khan, K. A. Suri et al., "In vitro antifungal activity of hydroxychavicol isolated from Piper betle L," Annals of Clinical Microbiology and Antimicrobials, vol. 9, article no. 7, 2010.

[23] S. Ganguly, S. Mula, S. Chattopadhyay, and M. Chatterjee, "An ethanol extract of Piper betle Linn. mediates its antiinflammatory activity via down-regulation of nitric oxide," Journal of Pharmacy and Pharmacology, vol. 59, no. 5, pp. 711718, 2007.

[24] S. Bandyopadhyay, B. Pal, S. Bhattacharya, M. Ray, and K. C. Roy, Extracts of piper betle leaves as immunomodulator, Google Patents, 2002.
[25] S. Bandyopadhyay, K. Roy, M. Ray et al., Herbal composition for treating CD33+ acute and chronic myeloid leukemia and a method thereof, Google Patents, 2003.

[26] K. Y. Pin, A. Luqman Chuah, A. Abdull Rashih, M. A. Rasadah, C. L. Law, and T. S. Y. Choong, "Solid-liquid extraction of betel leaves (Piper betle L.)," Journal of Food Process Engineering, vol. 34, no. 3, pp. 549-565, 2011.

[27] S. Rozen and H. Skaletsky, "Primer3 on the WWW for general users and for biologist programmers," Methods in Molecular Biology, vol. 132, pp. 365-386, 2000.

[28] A. Zainuddin, K. H. Chua, N. A. Rahim, and S. Makpol, "Effect of experimental treatment on GAPDH mRNA expression as a housekeeping gene in human diploid fibroblasts," $B M C$ Molecular Biology, vol. 11, article 59, 2010.

[29] S. O. Norfaizatul, C. Z. Zetty Akmal, A. K. Noralisa, S. M. Then, W. N. Wan Zunnah, and M. Musalmah, "Dual effects of plant antioxidants on neuron cell viability," Journal of Medicinal Plants, vol. 1, no. 33, pp. 113-123, 2010.

[30] D. Sarkar, S. Kundu, S. De et al., "The antioxidant activity of allylpyrocatechol is mediated via decreased generation of free radicals along with escalation of antioxidant mechanisms," Phytotherapy Research, vol. 27, no. 3, pp. 324-329, 2013.

[31] S. Makpol, T. W. Yeoh, F. A. C. Ruslam, K. T. Arifin, and Y. A. M. Yusof, "Comparative effect of Piper betle, Chlorella vulgaris and tocotrienol-rich fraction on antioxidant enzymes activity in cellular ageing of human diploid fibroblasts," $B M C$ Complementary and Alternative Medicine, vol. 13, article 210, 2013.

[32] F. Hazane, K. Valenti, S. Sauvaigo et al., "Ageing effects on the expression of cell defence genes after UVA irradiation in human male cutaneous fibroblasts using cDNA arrays," Journal of Phytochemistry and Photobiology. B, Biology, vol. 79, no. 3, pp. 171-190, 2005.

[33] L. J. Harvey and H. J. McArdle, "Biomarkers of copper status: a brief update," British Journal of Nutrition, vol. 99, supplement 3, pp. S10-S13, 2008.

[34] L. Wang, Y. Ge, and Y. J. Kang, "Featured article: effect of copper on nuclear translocation of copper chaperone for superoxide dismutase-1," Experimental Biology and Medicine, vol. 241, no. 14, pp. 1483-1488, 2016.

[35] Y. Manevich and A. B. Fisher, "Peroxiredoxin 6, a 1-Cys peroxiredoxin, functions in antioxidant defense and lung phospholipid metabolism," Free Radical Biology and Medicine, vol. 38, no. 11, pp. 1422-1432, 2005.

[36] M. Cui, Y. Huang, Y. Zhao, and J. Zheng, "New insights for FOXO and cell-fate decision in HIV infection and HIV associated neurocognitive disorder," Advances in Experimental Medicine and Biology, vol. 665, pp. 143-159, 2009.

[37] M. Monsalve and Y. Olmos, "The complex biology of FOXO," Current Drug Targets, vol. 12, no. 9, pp. 1322-1350, 2011.

[38] H. K. Kim, Y. K. Kim, I.-H. Song et al., "Down-regulation of a forkhead transcription factor, FOXO3a, accelerates cellular senescence in human dermal fibroblasts," Journals of Gerontology Series A: Biological Sciences and Medical Sciences, vol. 60, no. 1, pp. 4-9, 2005.

[39] H. Miyauchi, T. Minamino, K. Tateno, T. Kunieda, H. Toko, and I. Komuro, "Akt negatively regulates the in vitro lifespan of human endothelial cells via a p53/p21-dependent pathway," The EMBO Journal, vol. 23, no. 1, pp. 212-220, 2004.

[40] V. Nogueira, Y. Park, C.-C. Chen et al., "Akt determines replicative senescence and oxidative or oncogenic premature 
senescence and sensitizes cells to oxidative apoptosis," Cancer Cell, vol. 14, no. 6, pp. 458-470, 2008.

[41] X.-F. Qi, Z.-Y. Chen, J.-B. Xia et al., "FoxO3a suppresses the senescence of cardiac microvascular endothelial cells by regulating the ROS-mediated cell cycle," Journal of Molecular and Cellular Cardiology, vol. 81, pp. 114-126, 2015.

[42] T. M. Thornton and M. Rincon, "Non-classical p38 map kinase functions: cell cycle checkpoints and survival," International Journal of Biological Sciences, vol. 5, no. 1, pp. 44-52, 2009.

[43] M. Schreiber, A. Kolbus, F. Piu et al., "Control of cell cycle progression by c-Jun is p53 dependent," Genes and Development, vol. 13, no. 5, pp. 607-619, 1999.

[44] J. Campisi and F. d'Adda di Fagagna, "Cellular senescence: when bad things happen to good cells," Nature Reviews Molecular Cell Biology, vol. 8, no. 9, pp. 729-740, 2007.

[45] D. Choudhary and R. K. Kale, "Antioxidant and non-toxic properties of Piper betle leaf extract: in vitro and in vivo studies," Phytotherapy Research, vol. 16, no. 5, pp. 461-466, 2002.

[46] W. N. Wan Hasan, M.-K. Kwak, S. Makpol, W. Z. W. Ngah, and Y. A. M. Yusof, "Piper betle induces phase I \& II genes through Nrf2/ARE signaling pathway in mouse embryonic fibroblasts derived from wild type and Nrf2 knockout cells," BMC Complementary and Alternative Medicine, vol. 14, no. article 72, 2014. 

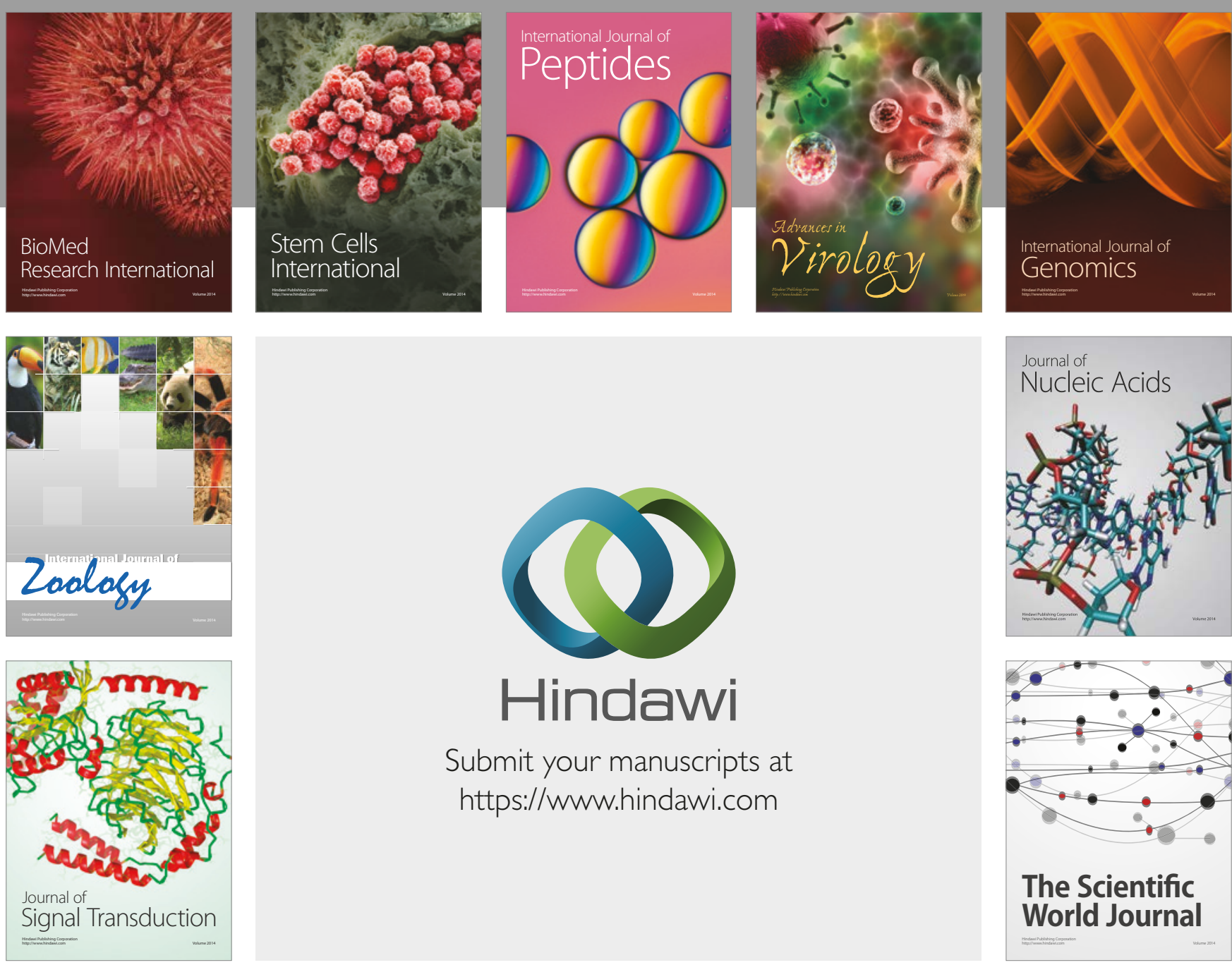

Submit your manuscripts at

https://www.hindawi.com
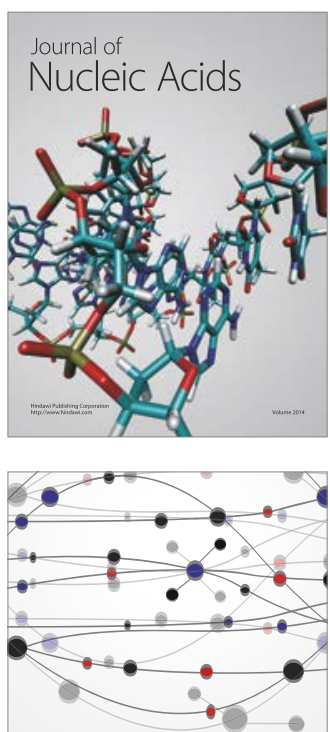

The Scientific World Journal

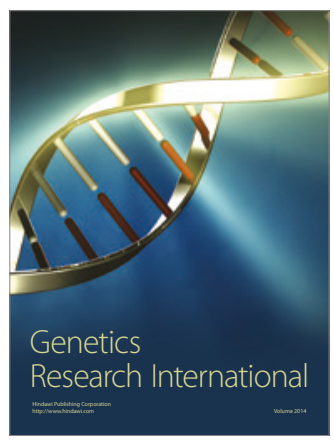

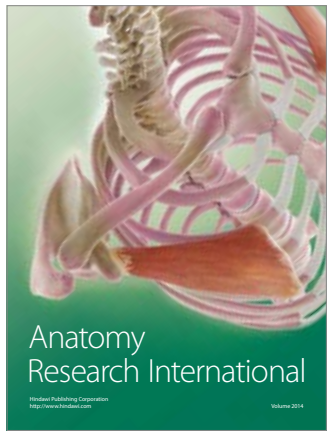

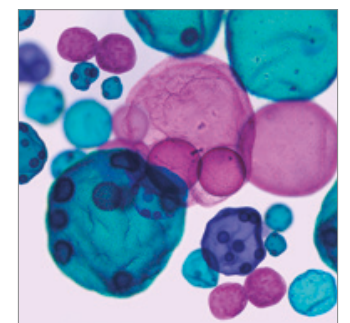

International Journal of Microbiology
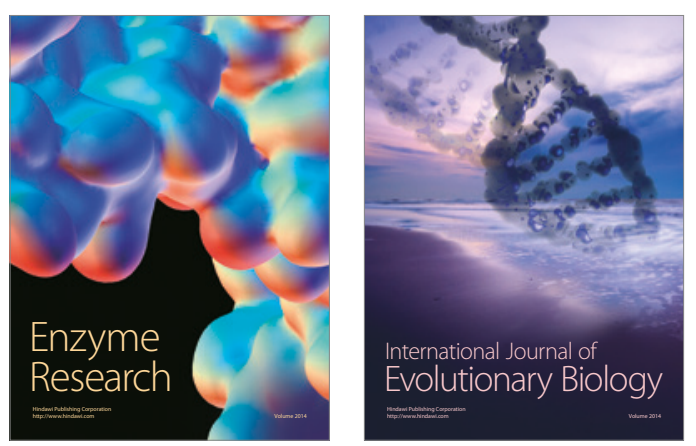
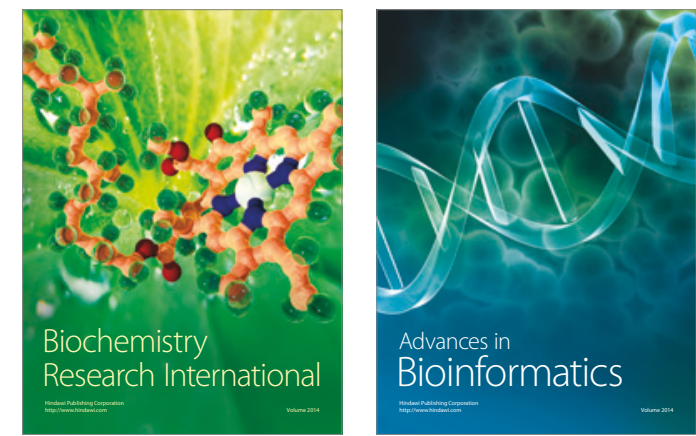

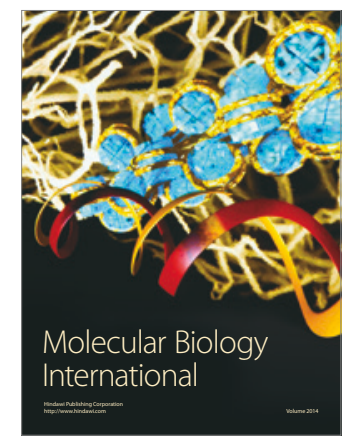

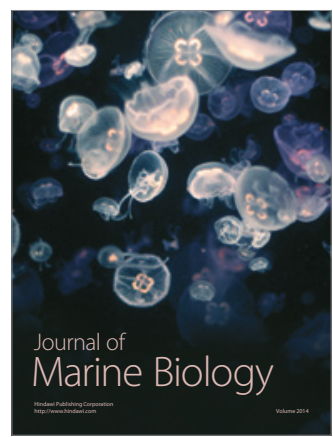

